\title{
Hemobiomarkers of health hazard potential of metal oxide nanoparticles
}

\author{
Gheith IM \\ Department of Medical Laboratories Technology, Faculty of Applied Medical Sciences, Taibah University, \\ Medinah, KSA. e.m.gheith@hotmail.com
}

\begin{abstract}
AIM: The study was designed to evaluate the possible adverse effects and consequences of metal oxide nanoparticles used on some major body organ functions and health parameters.

MATERIALS AND METHODS: Thirty albino rats, allocated randomly into three groups for experimental period of 20 days post-administration were used. Different effects of metal oxide nanoparticles were targeted including, thyroid, parathyroid, kidney, calcium, phosphate, hematological parameters and indices, as well as oxidative stress markers of the red blood cells and their membranes as alpha tocopherol and GSH, by using different analytical methods.

RESULTS: Data revealed thyroid and parathyroid hormonal disturbances; kidney dysfunction in the form of accumulation of some waste products as BUN, creatinine, and uric acid. A decrease in the calcium and phosphate and an increase in the potassium and phosphate concentrations was recorded. A marked decrease in the indices of anemia and diminished oxidative stress indicators were also evident, associated with marked increase in the total leukocyte count.

CONCLUSION: The present study confirmed the health risks of the use of metal oxide nanoparticles in the medical field without precautions and supervision; and may encourage application of nanoparticles from alternative origins, such as plants, algae, or microorganisms instead (Tab. 5, Fig. 4, Ref. 30). Text in PDF www.elis.sk.

KEY WORDS: nanoparticles, thyroid, parathyroid, kidney, oxidative stress, blood, green, alternative.
\end{abstract}

\section{Introduction}

This study was designed to investigate the possible health risks after using these extremely small-sized particles, which have became a real order in our life after proving their efficacy for the treatment of many diseases as radiotherapy. The authors mentioned that nanoparticles should be given intravenously as this route is the most suitable for nanoparticles administration and because of the ability of these particles to penetrate and spread intracellularly as well.

Despite its ability to treat many diseases and its availability now in many pharmaceutical products, strict instructions for their use in industry and medical field is a must to avoid their possible toxic effects; otherwise, safer alternative particles should be applied instead.

Producing companies must be honest in mentioning the conditioning of this technology, particularly, when used on a large scale and the possible side effects must be labelled, especially, when metal oxide particles are involved. The primary goals of

Department of Medical Laboratories Technology, Faculty of Applied Medical Sciences, Taibah University, Medinah, KSA, and Department of Biotechnology, Animal Health Research Institute, Dokki, Egypt

Address for correspondence: I.M. Gheith, PhD, Department of Medical Laboratories Technology, Faculty of Applied Medical Sciences, Taibah University, 344 Medinah, KSA. nano-bio-technologies using metal oxide, in particular, in drug delivery are: more specific drug targeting and delivery, reducing toxicity while maintaining therapeutic effects; greater safety and biocompatibility; and faster development of new safe medicines.

Despite the widespread use of Zinc Oxide ( $\mathrm{ZnO}$ ) nanoparticles, the most famous metal oxide form of nanoparticles (2), in a wide range of biomedical applications and in drug delivery as anti-cancer, anti-diabetic, antibacterial and antifungal (2), and as sun-protection product due to its ability to absorb ultraviolet rays; despite of that, a lot of studies demonstrated that the nanoparticles may be toxic depending on their small size properties, which may suggest them to be hazardous to the environment (2). The undesirable effects of $\mathrm{ZnO}$ nanoparticles are summarized below (Tab. 1).

To determine the toxicity of nanoparticles, the size and the surface area of particles must be noted (10). These criteria are considered to be responsible for the potential effect on human health and the environment; and may cause death if used at large concentrations. Low doses of $\mathrm{ZnO}$ nanoparticles, however, have not produced toxic effects in vivo .

New approaches and phenomena were discovered, which are safer, cost less, more friendly to the environment and human than metal oxide or chemical and physical methods. These are mainly exemplified by green nanoparticles, which were begun manufacturing using biosynthesis of green nanoparticles from plants, plant extracts and different microorganisms. For example, nanoparticles synthesized by honey mediated green methods, which provide po- 
Tab. 1. Reported undesirable effects of extensive use of $\mathrm{ZnO}$ metal nanoparticles.

\begin{tabular}{llc}
\hline$\#$ & Effect(s) & Reference \\
\hline 1 & Hazardous to the environment. & $(2)$ \\
\hline 2 & $\begin{array}{l}\text { Cytotoxic effects on various kinds of cells, in- } \\
\text { cluding osteoblastic cancer cells, human bron- } \\
\text { chial epithelial cells, kidney cells, alveolar ad- } \\
\text { enocarcinoma cells, hepatocytes and embryonic } \\
\text { kidney cells. }\end{array}$ \\
\hline 3 & $\begin{array}{l}\text { Toxic effects in vivo, high concentrations may } \\
\text { cause sudden death. }\end{array}$ \\
\hline 4 & $\begin{array}{l}\text { ZnO nanoparticles were more toxic than other } \\
\text { metal oxide nanoparticles such as Fe }{ }_{2} \mathrm{O}_{3}, \mathrm{Y}_{2} \mathrm{O}_{3},\end{array}$ \\
\hline \multicolumn{3}{l}{ TiO ${ }_{2}$ and CuO. } \\
\hline 5 & $\begin{array}{l}\text { ZnO nanoparticles produce cytotoxic effects in } \\
\text { various kinds of cells, including osteoblastic can- } \\
\text { cer cells, human bronchial epithelial cells, kidney } \\
\text { cells, alveolar adenocarcinoma cells, hepatocytes } \\
\text { and embryonic kidney cells; the nanoparticles' } \\
\text { effects may be related to particle size and dosage. }\end{array}$ \\
\hline 6 & $\begin{array}{l}\text { Oxidative stress was increased by ZnO nanopar- } \\
\text { ticles reactive oxygen species (ROS) }\end{array}$ \\
\hline 7 & $\begin{array}{l}\text { ZnO nanoparticles showed liver inflammation } \\
\text { and injury }\end{array}$ \\
\hline \multicolumn{4}{l}{ (2) } \\
\hline
\end{tabular}

tential and valuable end products with numerous applications in many fields providing a superior, ecofriendly alternative for harsh and toxic procedures of nanoparticles manufacture.

Nanoparticles produced by plants are more stable and their rate of synthesis is faster than that in the case of microorganisms. Moreover, the nanoparticles are more variable in shape and size in comparison with those produced by other organisms. The advantages of using plant and plant-derived materials for biosynthesis of metal nanoparticles have interested researchers to investigate the mechanisms of metal ions uptake and bio-reduction by plants, and to understand the possible mechanism of metal nanoparticle formation in plants (10).

This study tried to confirm the impact of the use of these ultra-structured particles that are synthesized by chemical or physical methods as zinc oxide on endocrine glands and different clinical, hematological parameters by using the model of albino rat as a symbol for human body to promote and encourage the use of green nanoparticles as a more friendly approach than the metallic one.

\section{Material and methods}

\section{Animal housing}

Male albino rats (aged 4 weeks; weighed 200-240 g) were used. The animals were kept in suitable laboratory cages, in tryto-keep the animal in stable environment in a ventilated room with maintained temperature, light and humidity. Food and water ad libitum and the $\mathrm{ZnO}$ nanoparticles were supplied in the food.

The rats were left for 14 days to adapt (adaptation period) to their new environment prior to receiving the nanoparticles and starting the experiment. After that, they were supplied with the experimental feeds for 20 days. All animal-handling procedures were performed according to the Guide for the Care and Use of Laboratory Animals; and all animal experiments were approved by the Experimental Animal Ethical Committee of by The European Commission Directive 86/609/EEC for ethics of animal experiments.

\section{Animal grouping}

The rats were assigned to 3 groups, 10 in each group, as follows:

Group I: that served as control and received regular rat feed, which contained feed ingredients as Basal diet: Oil, Yellow corn, Concentrate mixture, Soya bean meal, Wheat bran, Molasses, Common salt, Lysine, DL-methionine Min.-Vit. Premix and Ground limestone.

Group II: that received rat feed supplemented with $\mathrm{ZnO}$ nanoparticles at concentrations of $300 \mathrm{mg} / \mathrm{kg}$.

Group III: that received rat feed supplemented with $\mathrm{ZnO}$ nanoparticles at concentrations of $600 \mathrm{mg} / \mathrm{kg}$.

\section{Sampling \\ Blood samples}

On the 10th and the 20th days post-administration, blood samples were drawn into EDTA tubes, from orbital medial canthus venous plexus of the rats, and partitioned as follows:

The 1st part of blood sample was used to separate serum to measure:

1.Serum total $\mathrm{T} 3$ and $\mathrm{T} 4$, parathyroid hormones concentrations to evaluate the alterations in the corresponding endocrine glands by using commercial kits.

2.Serum biochemical parameters such as: blood urea nitrogen (BUN), uric acid and creatinine (CR), calcium, phosphorous, magnesium and potassium to evaluate the kidney function were carried out by different chemical kits obtained from Stanbio-laboratories ${ }^{\circledR}$ (USA) and Qumica Clinica Aplicada ${ }^{\circledR}$ (QCA ${ }^{\circledR}$, Spain).

The 2nd part of a blood sample was withdrawn and used as whole blood to estimate:

1.The possible alterations in erythrogram and leukogram. This was adopted by using Automated haematology analyzer, Mindray, China, to analyze the different parameters of erythrogram, including, Red blood cell (RBC) count, hemoglobin ( $\mathrm{Hb}$ ), PCV \%, Mean corpuscular hemoglobin $(\mathrm{MCH})$ and Mean corpuscular hemoglobin concentration (MCHC); and those of leukogram, including, white blood cells (WBC) and platelet counts.

2.The oxidative stress on RBCs and its membrane. This was adopted by measuring the activity of glutathione reductase (GHS) according to the method described by (1) and cited in (2) after isolation of erythrocytes and their membranes by the method of (1) with a slight modification cited in (2).

Membrane content of $\alpha$-tocopherol was determined after extracting with hexane. The hexane extracts were processed according to the method of and cited in (2) using bathophenanthroline, which forms a complex with ferrous ions.

\section{Tissue samples}

Autopsy samples were taken from the kidney, thyroid and parathyroid glands of rats in different groups and fixed in $10 \%$ formol 
Tab. 2. Hormonal disturbance and results of concentration of calcium and phosphorus in all the experimental groups $(\overline{\mathbf{X}} \pm \mathrm{SE}, \mathrm{n}=10, \mathrm{ANOVA}$, p $<0.05)$.

\begin{tabular}{|c|c|c|c|c|}
\hline \multirow[b]{2}{*}{ Parameters } & \multirow{2}{*}{$\begin{array}{c}\text { Sampling time } \\
\text { (day post administration) }\end{array}$} & \multicolumn{3}{|c|}{ Doses of Nanoparticles and grouping } \\
\hline & & Group I (basal diet) & $\begin{array}{c}\text { Group II (basal diet }+\mathrm{ZnO} \text { NPs, } \\
300 \mathrm{mg} / \mathrm{kg} \text { ) }\end{array}$ & $\begin{array}{c}\text { Group II (basal diet+ }+\mathrm{ZnO} \mathrm{NPs} \text {, } \\
600 \mathrm{mg} / \mathrm{kg} \text { ) }\end{array}$ \\
\hline \multirow{2}{*}{ T3 (ng/dl) } & 10th & $104.27 \pm 3.72$ & $63.71 \pm 3.30^{*}$ & $58.59 \pm 9.55^{*}$ \\
\hline & 20th & $96.87 \pm 3.74$ & $55.33 \pm 2.37 *$ & $45.65 \pm 3.43 *$ \\
\hline \multirow{2}{*}{$\mathrm{T} 4(\mu \mathrm{g} / \mathrm{dl})$} & 10th & $10.06 \pm 0.24$ & $9.26 \pm 0.14$ & $8.20 \pm 0.35^{*}$ \\
\hline & 20th & $10.15 \pm 0.43$ & $8.52 \pm 0.22$ & $7.35 \pm 0.51 *$ \\
\hline \multirow{2}{*}{ Parathyroid h. (pg/ml) } & 10th & $24.20 \pm 0.66$ & $21.44 \pm 1.81$ & $23.02 \pm 1.44$ \\
\hline & 20th & $22.27 \pm 1.30$ & $14.88 \pm 0.77 *$ & $15.49 \pm 0.24 *$ \\
\hline \multirow{2}{*}{ Calcium (mg/dl) } & 10th & $10.39 \pm 0.51$ & $9.93 \pm 0.33$ & $10.15 \pm 0.41$ \\
\hline & 20th & $11.23 \pm 0.51$ & $9.30 \pm 0.57$ & $8.46 \pm 0.25^{*}$ \\
\hline \multirow{2}{*}{ Phosphorus (mg/dl) } & 10th & $3.38 \pm 0.90$ & $3.66 \pm 0.49$ & $2.01 \pm 0.56$ \\
\hline & 20th & $3.98 \pm 0.81$ & $1.90 \pm 0.37 *$ & $1.80 \pm 0.13 *$ \\
\hline
\end{tabular}

*significantly different from the group I

Tab. 3. Results of different kidney function tests in all experimental groups $(\overline{\mathrm{X}} \pm \mathrm{SE}, \mathrm{n}=10, \mathrm{ANOVA}, \mathrm{p}<0.05)$.

\begin{tabular}{|c|c|c|c|c|}
\hline \multirow[b]{2}{*}{ Parameters } & \multirow[b]{2}{*}{$\begin{array}{c}\text { Sampling time } \\
\text { (day post administration) }\end{array}$} & \multicolumn{3}{|c|}{ Doses of Nanoparticles and grouping } \\
\hline & & Group I (basal diet) & $\begin{array}{l}\text { Group II (basal diet + ZnO NPs, } \\
300 \mathrm{mg} / \mathrm{kg} \text { ) }\end{array}$ & $\begin{array}{c}\text { Group II (basal diet+ZnO NPs, } \\
600 \mathrm{mg} / \mathrm{kg} \text { ) }\end{array}$ \\
\hline \multirow{2}{*}{ Creatinine (mg/dl) } & 10 th & $0.99 \pm 0.31$ & $0.83 \pm 0.37$ & $1.3 \pm 0.41$ \\
\hline & 20th & $0.52 \pm 0.008$ & $2.36 \pm 0.43 *$ & $2.56 \pm 0.18^{*}$ \\
\hline \multirow{2}{*}{ Uric acid (mg/dl) } & 10th & $4.09 \pm 0.28$ & $5.54 \pm 0.18$ & $5.58 \pm 0.73$ \\
\hline & 20th & $4.97 \pm 0.39$ & $7.74 \pm 0.34 *$ & $7.15 \pm 0.91 *$ \\
\hline \multirow{2}{*}{ Magnesium (mg/dl) } & 10th & $1.10 \pm 0.21$ & $0.75 \pm 0.05$ & $0.67 \pm 0.07 *$ \\
\hline & 20 th & $1.01 \pm 0.115$ & $0.59 \pm 0.03 *$ & $0.06 \pm 0.05^{*}$ \\
\hline \multirow{2}{*}{ Potassium (mg/dl) } & 10th & $4.87 \pm 0.33$ & $7.93 \pm 0.49 *$ & $8.34 \pm 0.63 *$ \\
\hline & 20th & $4.79 \pm 0.89$ & $8.66 \pm 0.44 *$ & $8.86 \pm 0.53 *$ \\
\hline
\end{tabular}

*significantly different from the group I

Tab. 4. Different hematological parameters in all experimental groups $(\overline{\mathrm{X}} \pm \mathrm{SE}, \mathrm{n}=10, \mathrm{ANOVA}, \mathrm{p}<0.05)$.

\begin{tabular}{|c|c|c|c|c|}
\hline \multirow[b]{2}{*}{ Parameters } & \multirow{2}{*}{$\begin{array}{c}\text { Sampling time } \\
\text { (day post administration) }\end{array}$} & \multicolumn{3}{|c|}{ Doses of Nanoparticles and grouping } \\
\hline & & Group I (basal diet) & $\begin{array}{l}\text { Group II (basal diet+ZnO NPs, } \\
\qquad 300 \mathrm{mg} / \mathrm{kg} \text { ) }\end{array}$ & $\begin{array}{l}\text { Group II (basal diet + ZnO NPs, } \\
600 \mathrm{mg} / \mathrm{kg} \text { ) }\end{array}$ \\
\hline \multirow{2}{*}{$\operatorname{RBCS}\left(10^{12} / \mathrm{L}\right)$} & 10 th & $7.80 \pm 0.34$ & $6.92 \pm 0.23$ & $6.63 \pm 0.20$ \\
\hline & 20th & $8.24 \pm 0.30$ & $6.51 \pm 0.47^{*}$ & $5.63 \pm 0.18 *$ \\
\hline \multirow{2}{*}{ PCV (\%) } & 10 th & $42.28 \pm 0.41$ & $37.41 \pm 1.08 *$ & $34.37 \pm 0.16^{*}$ \\
\hline & 20th & $40.88 \pm 0.37$ & $36.14 \pm 0.66^{*}$ & $34.45 \pm 1.01 *$ \\
\hline $\mathrm{Hb}(\mathrm{g} / \mathrm{dl})$ & 20th & $12.63 \pm 0.40$ & $8.18 \pm 0.51 *$ & $7.76 \pm 0.11 *$ \\
\hline \multirow{2}{*}{$\operatorname{MCV}(f l)$} & 10 th & $53.86 \pm 2.80$ & $54.14 \pm 1.37$ & $52.36 \pm 1.55$ \\
\hline & 20th & $52.13 \pm 3.73$ & $58.25 \pm 3.67$ & $59.92 \pm 2.67$ \\
\hline \multirow{2}{*}{$\mathrm{MCH}(\mathrm{pg})$} & 10 th & $16.00 \pm 0.66$ & $15.52 \pm 0.53$ & $15.23 \pm 0.75$ \\
\hline & 20th & $16.07 \pm 0.96$ & $13.29 \pm 1.57$ & $13.52 \pm 1.44$ \\
\hline \multirow{2}{*}{$\mathrm{MCHC}(\mathrm{g} / \mathrm{dl})$} & 10 th & $29.79 \pm 0.57$ & $28.76 \pm 0.57$ & $29.08 \pm 1.09$ \\
\hline & 20 th & $30.92 \pm 1.15$ & $22.71 \pm 1.70$ & $22.56 \pm 0.33$ \\
\hline WBCS $\left(10^{9} / \mathrm{L}\right)$ & 20th & $7.88 \pm 10.45$ & $9.59 \pm 0.11 *$ & $9.7 \pm 0.16^{*}$ \\
\hline \multirow{2}{*}{ Platelets $\left(10^{9} / \mathrm{L}\right)$} & 10th & $0.737 \pm 0.040$ & $0.668 \pm 0.039$ & $0.700 \pm 0.030$ \\
\hline & 20 th & $0.801 \pm 0.030$ & $0.598 \pm 0.032 *$ & $0.538 \pm 0.008^{*}$ \\
\hline
\end{tabular}

*significantly different from the group I

saline for twenty-four hours and micro-sections were prepared, stained and examined using conventional pathological procedure.

\section{Results}

Hormonal alterations in thyroid and parathyroid glands

The data in the Table 2 present alterations in the concentra- tions of $\mathrm{T} 3$ and $\mathrm{T} 4$, where the results of $\mathrm{T} 3$ showed a significant decrease on the 10th and the 20th days post administration in the groups II and III, while those of T4 showed a decline on the 20th post administration in the group III, when compared with those of the group I.

Parathyroid hormone results listed in the Table 2 and the statistical analysis of data revealed that there were no changes in the 
Tab. 5. Alterations of oxidative stress indicators in different experimental groups $(\overline{\mathrm{X}} \pm \mathrm{SE}, \mathrm{n}=\mathbf{1 0}, \mathrm{ANOVA}, \mathrm{p}<\mathbf{0 . 0 5})$.

\begin{tabular}{|c|c|c|c|c|}
\hline \multirow[b]{2}{*}{ Parameters } & \multirow{2}{*}{$\begin{array}{c}\text { Sampling time } \\
\text { (day post administration) }\end{array}$} & \multicolumn{3}{|c|}{ Doses of Nanoparticles and grouping } \\
\hline & & $\begin{array}{c}\text { Group I } \\
\text { (basal diet) }\end{array}$ & $\begin{array}{c}\text { Group II (basal diet + ZnO NPs, } \\
300 \mathrm{mg} / \mathrm{kg} \text { ) }\end{array}$ & $\begin{array}{c}\text { Group II (basal diet+ ZnO NPs, } \\
600 \mathrm{mg} / \mathrm{kg})\end{array}$ \\
\hline Erythrocyte membrane & 10th & $3.14 \pm 0.13$ & $3.03 \pm 0.47$ & $2.41 \pm 0.27 *$ \\
\hline$\alpha$-tocopherol ( $\mu \mathrm{g} / \mathrm{mg}$ protein $)$ & 20 th & $3.30 \pm 0.12$ & $2.45 \pm 0.25 *$ & $1.58 \pm 0.29 *$ \\
\hline Hemolysate total GSH & 10th & $11.44 \pm 0.54$ & $5.26 \pm 0.98 *$ & $4.87 \pm 1.02 *$ \\
\hline$(\mu \mathrm{mol} / \mathrm{gHb})$ & 20 th & $11.42 \pm 0.31$ & $6.07 \pm 0.37 *$ & $4.74 \pm 0.87 *$ \\
\hline
\end{tabular}

*significantly different from the group I

concentration of the hormone in the blood in the two administrated groups on the 10th day post administration with a remarkable significant decrease on the 20th day post administration in the groups II and III (at the end of experimental period).

\section{Alterations in calcium and phosphate serum levels}

Results mentioned in the Table 2 showed a significant decline in the calcium level in the serum in the group III on the 20th day of administration. Blood phosphate level was decreased in the two administrated groups at the end of experimental period.

\section{Alterations in kidney function}

As shown in the Table 3, uric acid and creatinine results revealed markedly significant increases in these body waste products on the 20th day post experiment in the two administrated groups. Concerning the level of potassium, the data listed in Table 3 revealed hyperkalemia in the groups II and III on the 10th and 20th days post administration, associated with hypomagnesaemia in the group II on the 20th day post administration; while in the group III on the 10th and 20th days.

\section{Erythrogram and leukogram alterations}

Some alterations were observed in the erythrogram and leukogram of rats in the treated groups. In comparison to the data of the group I, the changes in haemoglobin $(\mathrm{Hb})$ concentration, $\mathrm{PCV} \%$, RBCs count, the mean corpuscular volume (MCV) and the mean corpuscular hemoglobin $(\mathrm{MCH})$ and corpuscular hemoglobin concentration (MCHC) were recorded and analyzed in the Table 4. The indices of anemia, as RBCS count and $\mathrm{Hb}$ concentration, were significantly diminished in the groups II and III on the 20th day of administration. While on the 10th and 20th, lower PCV values were recorded.

The data of leukogram demonstrated the occurrence of leukocytosis in the group II and group III throughout the experimental period. Platelet counts revealed a significant decrease on the 20th day post administration in the groups II and III.

\section{Antioxidants status of blood and erythrocyte membrane}

The Table 5 indicates the antioxidant status of blood and erythrocyte membranes. GSH results recorded a decline throughout the experimental period in the two groups administrated with zinc oxide nanoparticles; while $\alpha$-tocopherol values were significantly decreased on the 20th day post administration in the groups II and III, when compared to the group I (Fig. 1).

\section{Histopathological findings}

The results of the histopathological examination of kidney, thyroid, and parathyroid in the group I revealed no abnormal

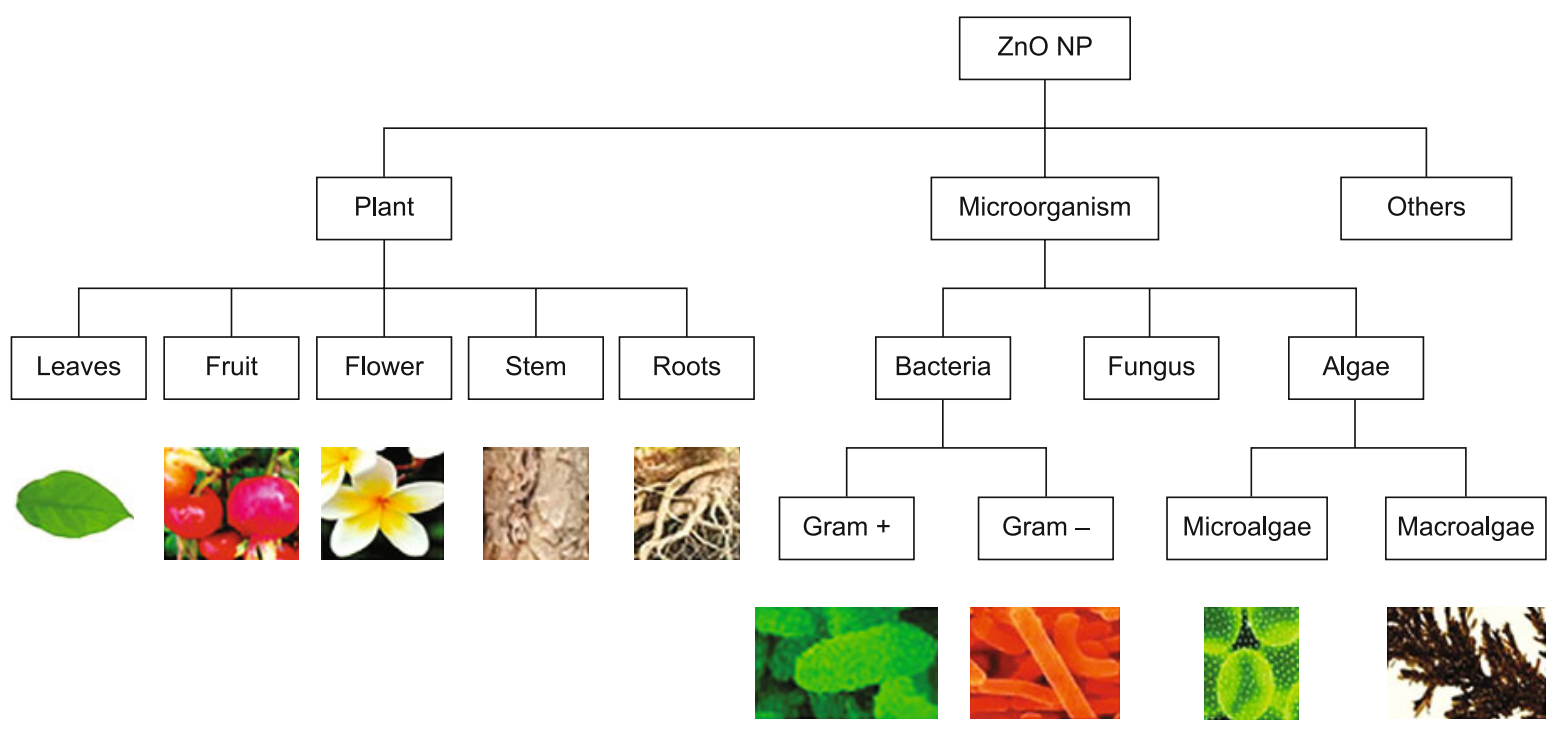

Fig. 1. Zinc oxide nanoparticle synthesis from different sources (Agarwal et al, 2017). 


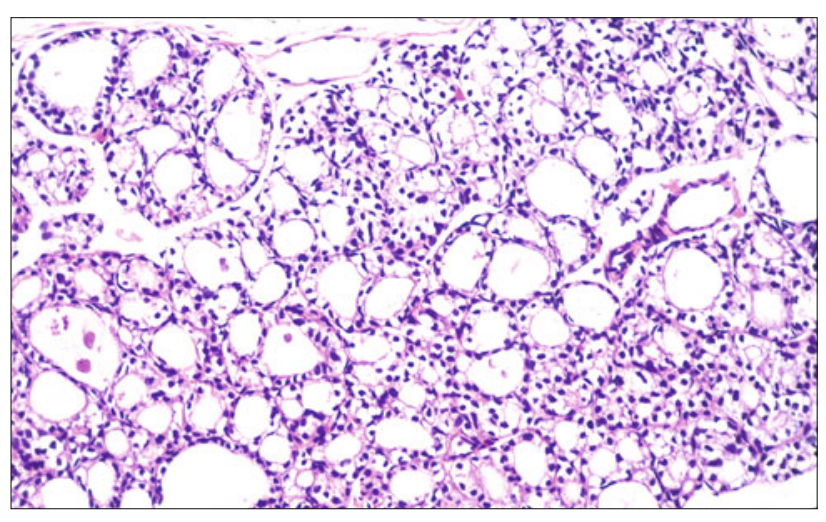

Fig. 2. Thyroid gland of a rat in Group III showing degeneration in the lining epithelium of the follicular with absence of the of the luminal collide.

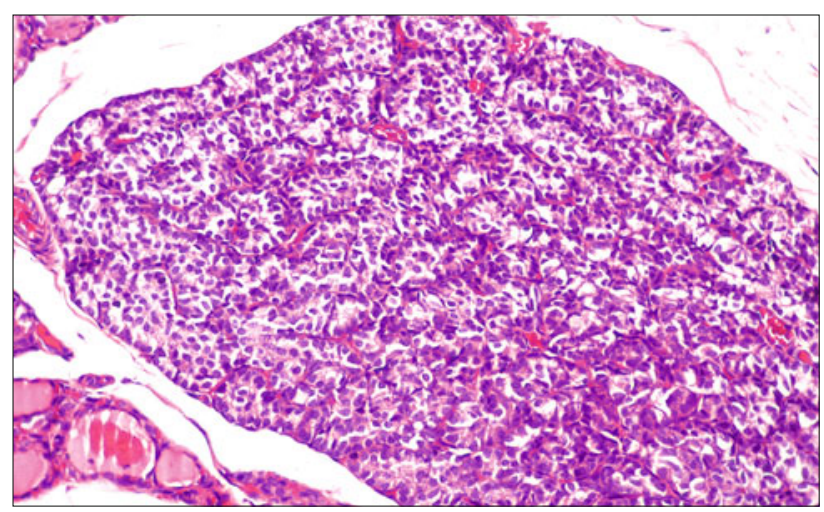

Fig. 3. Parathyroid gland of a rat in group III showing cellular vacuoles degeneration with congestion in blood capillaries in between.

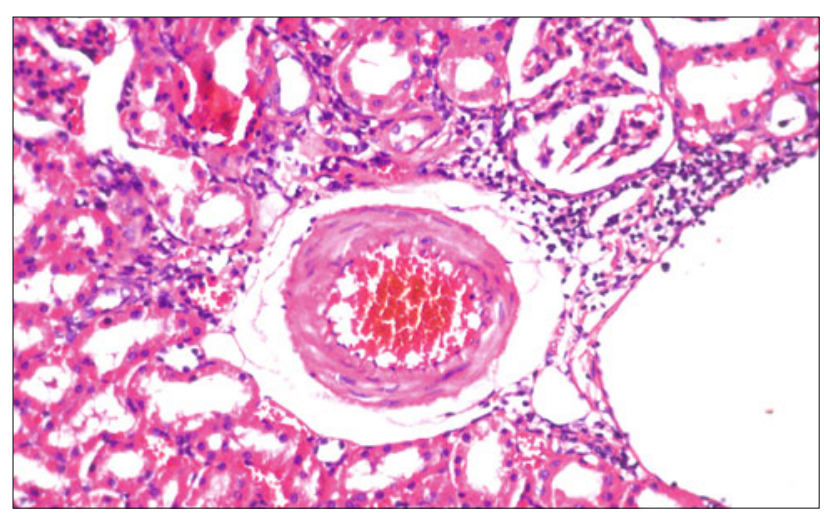

Fig. 4. Kidney of a rat in Group III showing focal inflammation Celle infiltration between tubules at cortico-medullary portion.

changes with a normal histological structure of the follicles and glomerulus and tubules at the cortex in thyroid gland and kidney, respectively. Meanwhile, the examined organs of the group II and group III showed histopathological alterations, which were more severe in the group III, when compared with those observed in the group II (Figs 2, 3 and 4).

\section{Discussion}

Along the revolution of nanotechnology and nanoparticle usage in different life fields including medical one, safety always remain of a great concern; that was the aim of the present trial.

The alterations in endocrine gland functions and hormones and the impact of zinc oxide nanoparticles (as model of metal oxide nano-particles of non-biological source) with escalating doses of administration were clarified by two clinical methods; the first was the significant decline in the concentration of hormones in serum and the 2 nd one was observation of histopathological lesions. Significant declines of the T3 and T4 hormones after administration of different doses zinc oxide support the results of histopathological lesions in the thyroid gland in experimental animals (Fig. 2). The follicular lining epithelium showed degeneration associated with the absence of the colloid from the follicular lumen (Fig. 2), and this may give an indication about the disturbance of basal metabolic rate plus all of the metabolic processes of different types of nutrients and, by rule, may affect the growth rate. These findings may draw the lines under the serious effects of zinc oxide nanoparticles on endocrine glands. In addition, this may be attributed to the effect of zinc oxide on TSH concentration, where a significant reduction in TSH was recorded after using of titanium dioxide as a model of nanoparticles in mice; this also may give an indication about the ability of these nano-particles to induce alterations in pituitary gland, the source of TSH (10). The pervious findings may support the results of the experiment performed by Vahid and others, which indicated that using of metal oxide nanoparticles as iron oxide at high concentration had toxic effects on thyroid gland and moreover might cause a disturbance (inhibition) of the activity of thyroid gland (23). The decline in thyroid hormones may be also attributed to the damage in the thyroid follicular cells that enclose rough endoplasmic reticulum, which synthesize the thyroglobin that constitutes the matrix of thyroid follicles, in which thyroid hormones are synthesized.

Regarding the parathyroid hormone, values were significantly diminished at the end of experimental period on the 20th day post-administration of the two doses of zinc oxide nanoparticles (Tab. 2). These declines may be attributed to the undesirable effect on parathyroid tissue of cumulated waste products from different metabolic processes and to the renal tissue dysfunction as recorded in Table 3. The disturbance in parathyroid hormone level may account for the disturbance of calcium (hypocalcemia) and phosphate level in the present experiment (Tab. 2). In addition to the degenerative changes in the parathyroid gland tissue, vacuolar cellular degeneration was also observed together with congestion of the blood capillaries in between follicles (Fig. 3). The role of the parathyroid hormone in maintaining the normal calcium level by its mastering actions on bone, kidney and intestine could be declined or even stopped upon $\mathrm{ZnO}$ nanoparticle administration causing hypocalcemia. Also, it may indicate a chief cell affection. Moreover, despite the decline in calcium level, the hypocalcemia levels, which are recorded in Table 2 cannot stimulate the chief cells to release the parathyroid hormone because of its pathological lesions as seen in (Fig. 3). 
Hypophosphatemia recorded in Table 2 might be explained due to the damage of kidney tubules and their inability to reabsorb phosphorus, which was then execrated in the urine, even with the presence of the hypoparathyrodism, which was mainly accompanied with an increased reabsorption rate of phosphate in healthy kidney. Hypocalcemia and hypophosphatemia related to hypoparathyroidism in the present study may also be attributed to the decline of renal tissue in secretion of calciferol hormone, which is the active form of vitamin $\mathrm{D}$ that increases the intestinal absorption of calcium. Also, might be due to the stoppage of the renal tissue in performing its function of reabsorption of nutrients. Moreover, it is a logic expectation that after a decline in the parathyroid hormone the vitamin D level is disturbed, which might be attributed to the stoppage of the role of parathyroid hormone in increase the activity of 1-alpha hydroxylase enzyme, which converts 25-hydroxycholecalciferol, the inactive form of vitamin D to its active form via action in kidney. Furthermore, the decline in vitamin D in the experimental animals suggest a tumor pathogenesis as recorded by (1), who mentioned a lot of studies supporting that vitamin D may play a major role in tumor pathogenesis, progression, and therapy.

The different degrees of histopathological alterations in the renal tissue recorded in (Fig. 4) including, focal inflammatory cells infiltration, was detected in between the glomeruli and congested blood vessels at the cortex (Fig. 4). This alteration may explain the recorded disturbances in homeostatic role of the kidney. The major roles of the kidney is in keeping homeostasis of the body acid-base balance, electrolyte concentrations, extracellular fluid volume, and blood pressure. The kidney accomplishes these homeostatic functions both independently and in concert with other organs, particularly those of the endocrine system. Various endocrine hormones coordinate these endocrine functions; these include renin, angiotensin-II, aldosterone, antidiuretic hormone, and atrial natriuretic peptide, among others. The above mentioned lesions in the renal tissue may explain the elevations of metabolic waste products in the body, as shown in Table (3), including creatinine and uric acid.

As for the potassium level, data revealed hyperkalemia and hypomagnesaemia, which act as indicator of change of filtration rate of kidney due to its pathological lesions, however the hyperkalemia may carry the risk of the depolarization of cardiac muscle and may cause cardiac arrest at any time.

The alteration in kidney function test plus the histopathological changes in renal tissue, mentioned earlier, may contribute also to the alteration in hematological parameters and induction of anemia. As the result of the cumulated waste products in the body, the undesirable effects on all of the body organs, especially bone marrow, the site of production of different blood cells, may occur. Moreover, the renal dysfunction may act as a contributor in the decline in secretion of erythropoietin hormone, which is the messenger to the bone marrow to produce more RBCs to compensate the decline in its count recorded in the Table 4.

In addition, the anemia indices listed in the table (4) of the groups II and III may be also attributed to hypothyroidism, which could cause certain forms of anemia (1). Also, hypothyroidism may be linked with some hemostatic abnormalities (1). Concerning the leukocytosis recorded in the groups II and III, this may be also the result of renal dysfunction and inflammation in agreement with that reported.

In the Table 4, the decline in the platelet counts in the groups II and III may not be parallel with the results of (25), who reported an increase in platelet counts after administration of 10 and $50 \mathrm{~nm}$ Gold Nanoparticles via intraperitoneal route. This result may indicate that the effect of nanoparticles differs according to the route of entrance to the body and according the type of metal administered.

Recently, Gaharwar et al (26) demonstrated that oxide nanoparticles as iron oxide nanoparticles induce oxidative stress in peripheral blood cells of rats. In this study, the oxidative stress in RBCs and their membranes were estimated by measuring two indicators, GSH and $\alpha$-tocopherol. Selection of GSH backs to its famous action as the master body antioxidant. The activity of glutathione reductase is used as the best indicator for oxidative stress. Also due to its critical and clinical role in protection of RBCs, hemoglobin and cell membranes against the different oxidative damages by oxygen free radicals (4). In normal condition, RBCs can resist the damage caused by oxidation, through the GSH secreted into plasma from the liver, and its transportation to other tissues via $\gamma$-glutamyl transpeptidase. The substance is also secreted from the kidney (2). Moreover, a protection against oxidative stress could be mediated by the cellular content of antioxidant enzymes, such as: catalase, superoxide dismutase, glutathione peroxidase (2). Additional way exhibited by RBCs for protection from the oxidative stressors is their rich content of $\alpha$-tocopherol in membranes (1). In the table (5), the analyzed data revealed a decline in the reduced-GSH, which may be attributed to the effect of zinc nanoparticles on the kidney, the main source of GSH. As for membranous $\alpha$-tocopherol in RBCs, its value was declined scientifically in the groups II and III at the end of experiment. These results may give an indication that RBCS may suffer from oxidative stress and a high rate of destruction and induction of haemolytic anemia is expected. Also, it refers that zinc oxide nanoparticles have the ability to modulate the normal antioxidant defense mechanisms of RBCs against the oxidative stress.

\section{Conclusion}

Depending on our own findings, we confirm different serious clinical effects of zinc oxide nanoparticles as the model of metal oxide nanoparticles; the assessed parameters, therefore, must be monitored during therapy with metal nanoparticles; using of green alternative source other than metal oxide is recommended.

\section{References}

1. Zhang X-D, Wu H-Y, Wu D, Wang Y-Y, Chang J-H, Zhai Z-B et al. Toxicologic effects of gold nanoparticles in vivo by different administration routes. Int J Nanomedicine 2010; 5: 771.

2. Lee SH, Pie J-E, Kim Y-R, Lee HR, Son SW, Kim M-K. Effects of zinc oxide nanoparticles on gene expression profile in human keratinocytes. Mol Cell Toxicol 2012; 8: 113-118. 
3. Hassani Sangani M, Nakhaei Moghaddam M, Forghanifard MM. Inhibitory effect of zinc oxide nanoparticles on pseudomonas aeruginosa biofilm formation. Nanomedicine J 2015; 2: 121-128.

4. Braydich-Stolle L, Hussain S, Schlager JJ, Hofmann M-C. In vitro cytotoxicity of nanoparticles in mammalian germline stem cells. Toxicol Sci 2005; 88: 412-419.

5. Ji JH, Jung JH, Kim SS, Yoon J-U, Park JD, Choi BS et al. Twenty-eight-day inhalation toxicity study of silver nanoparticles in SpragueDawley rats. Inhal Toxicol 2007; 19: 857-871.

6. Tang H-Q, Xu M, Rong Q, Jin R-W, Liu Q-J, Li Y-L. The effect of $\mathrm{ZnO}$ nanoparticles on liver function in rats. Int J Nanomedicine 2016; 11: 4275

7. Horie M, Nishio K, Fujita K, Endoh S, Miyauchi A, Saito Y et al. Protein adsorption of ultrafine metal oxide and its influence on cytotoxicity toward cultured cells. Chem Res Toxicol 2009; 22: 543-553.

8. Kang T, Guan R, Chen X, Song Y, Jiang H, Zhao J. In vitro toxicity of different-sized $\mathrm{ZnO}$ nanoparticles in Caco-2 cells. Nanoscale Res Lett 2013; 8: 496.

9. Azizi S, Ahmad MB, Namvar F, Mohamad R. Green biosynthesis and characterization of zinc oxide nanoparticles using brown marine macroalga Sargassum muticum aqueous extract. Mater Lett 2014; 116: 275-277.

10. Balasooriya ER, Jayasinghe CD, Jayawardena UA, Ruwanthika RWD, Mendis de Silva R, Udagama PV. Honey Mediated Green Synthesis of Nanoparticles: New Era of Safe Nanotechnology. J Nanomater 2017; 2017.

11. Iravani S. Green synthesis of metal nanoparticles using plants. Green Chem 2011; 13: 2638-2650.

12. Agarwal H, Kumar SV, Rajeshkumar S. A review on green synthesis of zinc oxide nanoparticles-An eco-friendly approach. ResourceEfficient Tech 2017.

13. EU directive E. Directive 2010/63/EU of the European Parliament and of the Council of 22 September 2010 on the protection of animals used for scientific purposes. Off J Eur Union L 2010; 276: 33-79.

14. Moron MS, Depierre JW, Mannervik B. Levels of glutathione, glutathione reductase and glutathione S-transferase activities in rat lung and liver. Biochim Biophys Acta 1979; 582: 67-78.

15. Rajasekaran NS, Devaraj NS, Devaraj H. Modulation of rat erythrocyte antioxidant defense system by buthionine sulfoximine and its reversal by glutathione monoester therapy. Biochim Biophys Acta 2004; 1688: 121-129.

16. Dodge JT, Mitchell C, Hanahan DJ. The preparation and chemical characteristics of hemoglobin-free ghosts of human erythrocytes. Arch Biochem Biophys 1963; 100: 119-130.
17. Desai ID. Vitamin E analysis methods for animal tissues. Methods Enzymol 1984; 105: 138-147.

18. Bancroft J, Stevens A. Enzyme histochemistry: theory and practice of histological techniques. New York: Churchill Livingstone 1996.

19. Yoosefi M, Shariat S, Golabi M, Safaei M, Heydari N, Kaji A et al. The effects of titanium dioxide nanoparticles on pituitary-gonad axis in male mice. J Chem Pharm Res 2015; 7: 720-723.

20. Babadi VY, Najafi L, Najafi A, Gholami H, Zarji MEB, Golzadeh J et al. Evaluation of iron oxide nanoparticles effects on tissue and enzymes of liver in rats. J Pharm Biomed Sci 2012; 23: 1-4.

21. Trump DL, Deeb K, Johnson CS. Vitamin D: considerations in the continued development as an agent for cancer prevention and therapy. Cancer J 2010; 16: 1 .

22. Chandel RS, Chatterjee G, Abichandani L. Impact of subclinical hypothyroidism on iron status and hematological parameters. Ann Pathol Lab Med 2015; 2: A21-A25.

23. Marongiu F, Barcellona D, Mameli A, Mariotti S (Eds). Thyroid disorders and hypocoagulability. Semin Thromb Hemost; 2011: C Thieme Medical Publishers.

24. Magaye RR, Yue X, Zou B, Shi H, Yu H, Liu K et al. Acute toxicity of nickel nanoparticles in rats after intravenous injection. Int J Nanomedicine 2014; 9: 1393.

25. Abdelhalim M, Moussa SA. The dimensional hematological alterations induced in blood of rats in vivo by intraperitoneal administration of gold nanoparticles. Nanomed Nanotechnol 2012; 3: 4.

26. Gaharwar US, Meena R, Rajamani P. Iron oxide nanoparticles induced cytotoxicity, oxidative stress and DNA damage in lymphocytes. $\mathrm{J}$ Appl Toxicol 2017.

27. Deneke SM, Fanburg BL. Regulation of cellular glutathione. Am J Physiol Lung Cell Mol Physiol 1989; 257: L163-L173.

28. Anderson ME, Bridges RJ, Meister A. Direct evidence for interorgan transport of glutathione and that the non-filtration renal mechanism for glutathione utilization involves $\gamma$-glutamyl transpeptidase. Biochem Biophys Res Commun 1980; 96: 848-853.

29. Sies H. Oxidative stress: oxidants and antioxidants. Exp Physiol 1997; 82: 291-295.

30. Burton GW, Joyce A, Ingold KU. Is vitamin E the only lipid-soluble, chain-breaking antioxidant in human blood plasma and erythrocyte membranes? Arch Biochem Biophys 1983; 221: 281-290.

Received November 2, 2019. Accepted December 9, 2019. 